Exploring the mathematics of motion through construction and collaboration (2006) Journal of Computer Assisted Learning, 22, pp114-136

\title{
Exploring the mathematics of motion through construction and collaboration
}

\author{
Gordon Simpson, Celia Hoyles \& Richard Noss
}

London Knowledge Lab, Institute of Education, University of London, UK

\section{Abstract}

In this paper we give a detailed account of the design principles and construction of activities designed for learning about the relationships between position, velocity and acceleration, and corresponding kinematics graphs. Our approach is model-based, that is, it focuses attention on the idea that students constructed their own models - in the form of programs - to formalise and thus extend their existing knowledge. In these activities, students controlled the movement of objects in a programming environment, recording the motion data and plotting corresponding position-time and velocity-time graphs. They shared their findings on a specially-designed web-based collaboration system, and posted cross-site challenges to which others could react. We present learning episodes that provide evidence of students making discoveries about the relationships between different representations of motion. We conjecture that these discoveries arose from their activity in building models of motion and their participation in classroom and

online communities.

\section{Keywords}

Communication; Programming; Mathematics; Modelling; Science

Learning process: Group; Individual 
Exploring the mathematics of motion through construction and collaboration (2006) Journal of Computer Assisted Learning, 22, pp114-136

Level and place of learning: Secondary

Research/evaluation paradigm: Illuminative; Qualitative

Content: Kinematics; Graphs; Motion

\section{Introduction}

In this paper we give a detailed account of the design principles and construction of activities designed for learning about the relationships between position, velocity and acceleration, and corresponding kinematics graphs. Our approach is model-based, that is, it focuses attention on the idea that students constructed their own models - in the form of programs - to formalise and thus extend their existing knowledge. The study formed part of a large-scale three-year EU-funded research project, WebLabs, which involved the iterative design of two systems: a programming-based environment for students to build models of their mathematical and scientific knowledge, and a set of web-based collaboration tools with which they could share both their ideas and their programmed models. The students were aged between 10 and 14 years, and spanned six EU countries.

Working with graphs is a fundamental requirement for science learning, and kinematics graphs, in particular, are widespread as a teaching tool in physics. Kinematics graphs are characterised by plotting position, velocity or acceleration on the y-axis and time along the x-axis. Our study was limited to position-time and velocity-time graphs. The students involved had little formal exposure to time-based graphs during schooling, or to the machinery of algebra or calculus, so our concern was to design activities that focussed on the relationship between narrative (textual and verbal) descriptions of motion and their corresponding graphs, rather than on calculations. Our aim was to encourage students to 
Exploring the mathematics of motion through construction and collaboration (2006) Journal of Computer Assisted Learning, 22, pp114-136

articulate these relationships both in terms of their formalisations (as elements of computer programs) and in their spoken interactions both within their classroom site, and across the net.

\section{The study of kinematics}

There is no shortage of studies that catalogue students' difficulties in the area of understanding kinematics graphs: McDermott et al. (1987) categorised ten areas, while Beichner (1994) identified six. Of the latter, two are particularly salient, namely the 'graph as picture error' (see also, Janvier, 1981), and 'variable confusion'. The 'graph as picture' error is one in which a graph is seen much like a photograph of the situation, rather than a mathematical representation of the event (so, for example, 'hills' in the graph are seen as hills on land). In 'variable confusion', students fail to distinguish between position, velocity and acceleration, either because they appear not to have a clear understanding of the differences between these variables, or because they do not pay sufficient attention to, or do not understand the meaning of the label on the y-axis.

Beichner (1994) claims that traditional kinematics instruction does little to improve student's understandings of graphs. His work belongs to a widespread way of conceiving students' difficulties as 'misconceptions' or 'alternate conceptions', which claims to identify the models that naïve learners hold about the world, and how this knowledge differs from that of formal physics (e.g. McCloskey, 1983; McDermott, 1984; see also, Confrey, 1990 for a critical view). There are alternative views that would allow a more central role for instruction. For example, diSessa $(1988,1993)$ proposes that prior knowledge is distributed over a number of phenomenological primitives, or 'p-prims'. P- 
Exploring the mathematics of motion through construction and collaboration (2006) Journal of Computer Assisted Learning, 22, pp114-136

prims have the following general features: they are simple abstractions from common experience; they are connected to each other via complex networks and may contradict one another; activation of a particular p-prim is context dependent; and most importantly from a design point of view, although p-prims are permanent and cannot simply be replaced, the contexts under which they are activated can be changed.

Of the many studies that have reported positive learning gains in this area a consistently productive approach has been in the use of microcomputer-based laboratory (MBL) tools, which involves the linking of sensor equipment to computer software that allows the realtime generation of graphs. Students typically move some part of their body (e.g. hand) and observe the corresponding changes in position-time or velocity-time graphs, and this, it is claimed, would achieve a deeper appreciation of the relationships involved (see Nemirovsky, Tierney, and Wright, 1998). In fact, Mokros and Tinker (1987) suggest 'graph as picture' and slope/height confusion (confusing the meaning of the slope of a line and the height of a point on a line) are very easy to 'overcome' using MBL instruction. Similarly, Arzarello \& Robutti (2004) argue that distance-time and velocity-time graphs can be understood provided students can live and share their conceptual genesis.

Work that recently has linked with the MBL-style approach, has been undertaken by the SimCalc group (see, for example, Hegedus \& Kaput, 2004) and promises to elaborate how students using graphing in SimCalc can, for example, develop an understanding of slope-as-rate-of-change by sharing their constructions in the classroom. We see this work, like our own, as primarily constructing novel ways for learners to create their own representations of what they see (and touch and feel), rather than to persist in postponing 
Exploring the mathematics of motion through construction and collaboration (2006) Journal of Computer Assisted Learning, 22, pp114-136

the study of interesting phenomena until some future time when algebra has been mastered (for a discussion of how a group of students went about creating and refining their own static representations of motion, see diSessa et al., 1991) ${ }^{1}$.

This brief overview of the available literature indicates a heterogeneity of views concerning what constitutes learning in the domain, how one should set about designing for it, and how one might expect to discern it. It is unsurprising that the design of technology-based environments for the study of motion is necessarily shaped by the way knowledge and its growth is perceived - implicitly or explicitly. Our own view, which will inform what follows, is associated with the programme of constructionist learning (Harel and Papert, 1991), which argues, quite simply, that individuals learn effectively when they are simultaneously building (typically, but not exclusively, 'programming' in some form) external realities 'out there' to support and foster the construction of internal meanings. The constructionist approach maintains, as an additional focus, that constructing for an audience adds a further dimension to learning design, and that the process of mutual reflection on built artefacts is a key imperative. We have borrowed substantially from this theoretical agenda to frame the research reported below.

\footnotetext{
${ }^{1}$ Given this focus for our work, we do not contribute here to the debate over the importance of the real-time aspect in students' activities: some studies have claimed it is crucial to learning (Brasell, 1987) while others have found no learning differences between real-time and delayed-time display and analysis of kinematics graphs (Beichner, 1990; Brungardt \& Zollman, 1995).
} 
Exploring the mathematics of motion through construction and collaboration (2006) Journal of Computer Assisted Learning, 22, pp114-136

\section{Design principles of the study}

We have based the design of our system around a programming language, ToonTalk (for an extended rationale for the use of programming for students, and a history of the research in this field within mathematical education, see Noss \& Hoyles, 1996). ToonTalk is a fully functional, concurrent programming language that has an interface modelled in the style of a video game (Kahn, 1996, 1999; see www.toontalk.com) ${ }^{2}$. For example, to create a program, one teaches a 'robot' by giving it an example (see Cypher, 1993) - directly leading it through the steps of the task it is to perform. The robot remembers what it was trained to do, and can be generalised from the specific example on which it was trained to deal with more general cases. All this is accomplished without text, as objects are referred to by their position ('this one here') rather by name ('the object called $\left.x^{\prime}\right)$.

We are well aware that this description does not convey the sense of what it means to construct or interpret a program in ToonTalk, not least because programs are not available for 'inspection' in the traditional way (there is no text); the only way to read a program is to see it run. We do, however, invite the interested reader to make use of the information that is readily available: for a computer science description of ToonTalk, papers describing how the language works, and a trial version, see www.toontalk.com. We will also, in what follows, give examples of how we exploited and built upon the programming substrate of ToonTalk, and this will, we hope, provide a further sense of

\footnotetext{
${ }^{2}$ In ToonTalk, every computational abstraction is concretized as an animated cartoon object. Interaction with the key ideas of programming - variables, constants, program storage, transmit and receive capabilities - all have a counterpart that fits within a game-like metaphor.
} 
Exploring the mathematics of motion through construction and collaboration (2006) Journal of Computer Assisted Learning, 22, pp114-136

the system as a whole (see weblabs.eu.com for an overview of the WebLabs project, the role of ToonTalk, and the designed activities).

Alongside the development and extension of the ToonTalk programming language, we also developed a web-based collaboration system called WebReports, which allows students to share and discuss not only their current thoughts and findings, but working models that instantiate their ideas. Students compose online reports using a wysiwyg editor, which includes the facility to embed files such as pictures (e.g. Excel graphs), java applets, and ToonTalk objects. Students can also discuss one another's reports using an extensive commenting functionality. A comment can be posted at the bottom of any webreport page, and may include new pictures or ToonTalk models. Comments can be posted as replies to other comments so that threads of discussion are created. We describe in more detail elsewhere the details of the components of the WebLabs approach (Simpson et al, 2005; Mor, Tholander \& Holmberg, in press; Hoyles and Noss, in press). In addition to the development of modelling tools and a web-based system for communication, we also designed activity sequences for students that encouraged them to model and share mathematical and/or scientific ideas.

We now describe one activity sequence that involved using, constructing and interpreting kinematics graphs. Its starting point was the development of a Lunar Lander, an activity borrowed from a popular video game first released by Atari in 1979 in which players control the movement of a rocket, attempting to descend onto landing-pads, while avoiding obstacles and rationing their fuel use. We used this as the motivation for exploring position, velocity, acceleration, and the graphing of the first two variables over 
Exploring the mathematics of motion through construction and collaboration (2006) Journal of Computer Assisted Learning, 22, pp114-136

time. The lunar lander sequence was the second we designed in the domain of the mathematics of motion, following a set of activities involving 1-dimensional collisions (Simpson et al, 2005): and the design of the current activities was informed by this previous experience. The activities were jointly developed and tested by teams in Cyprus and London.

Our main learning aim was that through constructing the properties of the lander that were necessary for successful landing, students would engage with the concepts of position, velocity and acceleration, and develop a richer appreciation of these concepts and the relationships between them. By actually building the lander's motion behaviour, we anticipated that students would be able to describe how position and velocity varied over time, and be able to read and interpret the associated graphs.

At this point, it is important to clarify the difference between our activities and the traditional 'lander' game. In the traditional simulation, players can choose the values of variables (how much fuel, allowable landing speed, gravitational force etc.) and watch what happens. In our version, students compare and contrast motion events that they themselves have constructed, so that they could manipulate the values of variables, but also choose what variables they thought were important, and how these variables were related by observing the movement and the kinematics graphs produced from it.

There are several aspects of our research that distinguish it from other studies: we point here to two. First, we developed ToonTalk so that we could create 'behaviours' (pieces of program that could be given to any object to behave in a specified way). These behaviours are placed on the 'back' of the lunar lander, and by 'flipping' the lander, they 
Exploring the mathematics of motion through construction and collaboration (2006) Journal of Computer Assisted Learning, 22, pp114-136

can be inspected or modified. This afforded the possibility of students engaging at different 'layers' of complexity - watching the model run, making fine adjustments to a subset of its parameters, modifying existing 'code' (the quote marks are necessary as ToonTalk code is non-textual) or building programs from scratch ${ }^{3}$. These different layers potentially afforded a variety of learning possibilities, and while we do not claim that all students engaged with all layers, we have 'existence theorems' that indicate that many did indeed access the system at a variety of entry-points at different times in their learning, and for different purposes.

We decided to use Microsoft Excel for the production of the kinematics graphs, because of its familiarity in classrooms. We therefore devised a tool (written in ToonTalk) through which data from running ToonTalk models, such as velocity and position, could be collected and exported to Excel (see Figure 2). Thus students could simultaneously see the results of their models, while maintaining a clear distinction between the behaviour of the objects themselves and the graphical representation of that behaviour (generated by Excel $)^{4}$. In this way, running the system would allow students to see two different representations that they had created: first, the movement of ToonTalk objects; and second, position-time and velocity-time graphs plotted from the exported data.

\footnotetext{
${ }^{3}$ Furthermore, the distinctions between program creation, program execution and manipulation of elements are blurred in ToonTalk, due to its unique concurrent, animated, and non-textual nature.

${ }^{4}$ Technical note. The system was set up so that data was transmitted invisibly in real time from the objects of the model, as they ran; and then automatically received by the spreadsheet. Like all ToonTalk objects, this is achieved in a cartoon-like manner: a bird (on the model) flies to her nest (connected to the spreadsheet).
} 
Exploring the mathematics of motion through construction and collaboration (2006) Journal of Computer Assisted Learning, 22, pp114-136

In summary, by giving students the raw material by which they could construct, explore and share their models, we attempted to build upon and enrich what they already knew about motion, and above all, to formalise their intuitive knowledge base. We describe this attempt below, by sharing the results of an iteration of a design experiment, a method which, as Cobb et al. (2003) put it, aims to improve understanding of a learning system or ecology, 'by designing its elements and by anticipating how these elements function together to support learning' (ibid, p. 9).

\section{Methodology}

We report here on the iterative design of activities that were undertaken by two groups of students, one based in London and the other based in Nicosia, Cyprus. While the general thread of activities on the two sites was similar, we cannot claim that the two groups followed exactly the same trajectory, or that the pedagogical approach, educational background or age profile in the two sites was identical. The data and analyses reported here is derived from the London site. However, we will see that there is at least one point in the activity sequence where Cyprus-London web-based collaboration played an important part in the learning process. This took place during a full-day workshop at he University in London.

In London, we worked with a group of seven boys aged between 13 and 14 years attending a North London boys' secondary school. The activities took place over seven 90-minute weekly after-school sessions held at the school computer lab, and one full-day workshop held at a computer lab at the Institute of Education. The students were selected by their mathematics teacher, who informed us that they were among the highest- 
Exploring the mathematics of motion through construction and collaboration (2006) Journal of Computer Assisted Learning, 22, pp114-136

achieving students within this inner-city school. Attendance was voluntary: three students attended all the sessions, and all but one of the others attended four or more. All the students attended the full-day workshop. The same students had previously completed WebLabs activities on a different topic - number sequences - and were therefore already familiar with our approach and the tools used, both ToonTalk and WebReports. Two researchers conducted the sessions and were jointly responsible for capturing data; their mathematics teacher was sometimes present but only peripherally involved.

The Cyprus team worked with 14 students aged 13. Students were divided into two groups and each group participated in 90-minute sessions twice a week at the computer centre at the University of Cyprus. Student attendance was voluntary and some had previously taken part in number sequence or $1 \mathrm{D}$ collisions activities. Three researchers conducted the sessions: in both sites, the role of the researchers was as participant observers, who intervened when requested by the students, and who acted as support for their activities.

Data was captured by: audio-recorded interactions (sometimes very difficult in a noisy environment); short on-task interviews, designed on-the-fly to probe interactions between students and between student and computer, as they occurred; video-recording of the fullday workshop in London; and field notes. The latter were transcribed shortly after each workshop, and discussed by the research team. In addition, we were able to draw on the models students had built, and the computer-generated WebReports posted on the WebLabs site (some idea of what these reports involved for students can be gauged by visiting www.weblabs.org.uk/wlplone). 
Exploring the mathematics of motion through construction and collaboration (2006) Journal of Computer Assisted Learning, 22, pp114-136

Finally, in the first session we gave all the students a subset of the Test of Understanding Graphs in Kinematics (TUG-K: see Appendix A) developed by Beichner (1994), as a preactivity questionnaire to obtain responses that could provide a focus for initial group discussions. The test was also given after the activities, a post-activity questionnaire. It was not used as a 'post-test' but rather intended to assist us in gaining a picture of how the students' knowledge might have evolved in general during the course of the activities as well as be better able to trace individual student learning trajectories ${ }^{5}$.

\section{The design of the activities}

The sequence of activities and accompanying tools was iteratively designed, tested and refined in several cycles in both teams, using the methodology of the design experiment referred to earlier (Figure 1). In London, we recognised the need to motivate the students to take part in the activities, and students took part voluntarily and in their own time. Hence, one of the key motivations we employed at the outset was that after completing six preparatory activities the London students would be given the opportunity to build and play their own versions of a lunar lander game in ToonTalk (in Cyprus, this motivation was, it seems, not needed). An additional motivation for both groups was the prospect of cross-site interaction with the other group, mainly during the Guess my graph challenge that we describe below.

[INSERT FIGURE 1 HERE]

\footnotetext{
${ }^{5}$ In what follows, we will occasionally refer to some of this data, but we should emphasise that it was not used for pre-post testing, or to infer directly the learning outcomes of the activities.
} 
Exploring the mathematics of motion through construction and collaboration (2006) Journal of Computer Assisted Learning, 22, pp114-136

We now describe each activity in further detail ${ }^{6}$.

\section{Investigating motion, acceleration and graphing: Individual tasks}

The first activity, Exploring motion and plotting graphs introduced the idea of time-based motion graphs, and the methods for controlling, observing and recording motion in ToonTalk. The aim was for students to gain a feel for the data generated by an object whose motion they controlled using ToonTalk 'sensors' ${ }^{7}$. The Investigating and plotting acceleration activity was intended to build on students' existing knowledge, extending it to include the idea of acceleration and develop familiarity with the corresponding ToonTalk acceleration tool. Figure 2 shows a screenshot of the lander and the sensors attached to it. Position, speed and acceleration of the lander are shown in the boxes indicated, but can also be manipulated by simply typing in new values (sensors are twoway: they provide readouts, but also can be used as input).

Data from the values of one of the sensors during the motion of the lander can be sent to Excel using the Export to Excel tool, which allowed students to plot graphs of the data generated as their model ran. The aim was that they could discover, for example, that constant acceleration corresponds to a curve on a position-time graph, and a straight line on a velocity-time graph.

[INSERT FIGURE 2 HERE]

\footnotetext{
6 We have authored an accompanying webreport (http://tinyurl.com/81ve4) designed to elucidate the activities further through the use of video.

${ }^{7}$ Any ToonTalk object has a set of sensors, which provide readouts of its state (e.g. its position, size etc.)
} 
Exploring the mathematics of motion through construction and collaboration (2006) Journal of Computer Assisted Learning, 22, pp114-136

In Predicting graphs after observing motion, students had to give a pre-programmed 'car' an initial position and speed and observe its motion (see Figure 3). They were then asked to predict and draw the corresponding position-time and velocity-time graphs. They then actually plotted the graphs using the Excel tool and compared these plots with their predictions. Each car was pre-programmed to behave differently: for example, accelerating, decelerating or moving at constant speed. The aim was for students to engage in a cycle of prediction, testing and evaluation, to help them to link what they saw in a car's behaviour, the graphs of the time-dependent functions, and the programs (as behaviours) for generating its movement. We also included this activity to vehicle motion with which they were more familiar, i.e. car motion rather than the lunar lander, and further, by considering motion in the horizontal direction as opposed to the vertical motion of the lander, we intended to probe a little more deeply what kind of understandings the students had for acceleration.

\section{[INSERT FIGURE 3 HERE]}

\section{Interpreting graphs: a collaborative task at a distance}

The Guess my graph challenge ${ }^{8}$ was specifically included in the activity sequence to promote cross-site collaboration. It was a joint activity at a distance, designed to encourage explicit description of the motion represented by a kinematics graph. The basic format was that students at one site set challenges for students at a distant site, and vice versa, to start threads of discussion and comparison. Here, students at one site controlled

\footnotetext{
${ }^{8}$ Students played a game of similar format but in a different context to one they had experienced in a previous phase of the research. (The Guess my robot game worked well in the number sequences activities: Mor et al, 2004).
} 
Exploring the mathematics of motion through construction and collaboration (2006) Journal of Computer Assisted Learning, 22, pp114-136

their lunar lander in ToonTalk (Figure 2), recorded the data, and produced kinematics graphs in Excel. They posted their graphs in Webreports and challenged students at the other site to use their own landers to reproduce them.

When attempting to solve a challenge, students needed to consider a number of issues. First, they had to determine which variable was plotted and to get a feel for the type of motion that had given rise to the graph. Next, they had to consider how to model this motion in ToonTalk. For example, was acceleration required and what were the initial conditions of position and velocity? Once determined, students set up their ToonTalk model, recorded the data and exported it to Excel. In Excel, they plotted the data on a graph and then compared it with the challenge to evaluate whether it was 'correct'. This was designed to prompt discussion of what constituted correctness. We deliberately left this open-ended in our design. At this point, if the students were happy with their graph, they posted it as a response on the WebReports site, ideally with an accompanying description of the relevant ToonTalk conditions used. If they felt their graph did not match, they could return to ToonTalk to refine their model, repeating the process until such time as they were satisfied. Students sometimes worked in pairs, in which case they collaborated face-to-face before sharing their end products at a distance. Once a response to a challenge had been posted, we hoped that the challenger(s) would respond in turn, perhaps asking for clarification, pointing out differences, or comparing the methods of graph production. 
Exploring the mathematics of motion through construction and collaboration (2006) Journal of Computer Assisted Learning, 22, pp114-136

\section{Comparing representations of motion: a collaborative face-to-face task}

The idea of the Matching different descriptions activity was for students to work collaboratively in one site to match corresponding narrative, position-time graph, velocity-time graph and ToonTalk 'sensor' representations of the same motion event (this task was only carried out in London). The aim was that the group would have to make explicit the relationship between the types of representation and justify them. These four different representations were presented as a set of shuffled cards. There were six different motion events, and the four representations for one particular event are shown in Figure 4. Note that the narrative description is simply a natural language description of the motion event, while in the previous modelling activities ToonTalk was the medium for viewing the events, with the changing sensor values providing a dynamic quantitative display of the relevant variables. Students collaboratively completed this task in groups of two or three.

\section{[INSERT FIGURE 4 HERE]}

\section{Programming a lunar lander game}

In Exploring force and acceleration, students experimented with a pre-built tool (Figure $5)$ instantiating Newton's second law $(F=m a)$. This tool allowed the acceleration of a lunar lander to be controlled by setting the amount of boost force and the lander 'size': a proxy for mass (like everything else in ToonTalk, the size of an object can be controlled directly by manipulation, or by setting the values of parameters). In this way, students could consider not only the abstracted motion of the lander (kinematics), but the 
Exploring the mathematics of motion through construction and collaboration (2006) Journal of Computer Assisted Learning, 22, pp114-136

underlying causes of motion (dynamics) in terms of the force and mass that are present in the world.

The primary aim of this activity was to serve as in introduction to the concepts and tools that were used in the final Lunar lander game-making activity. Hence our decision to provide students with a pre-built tool that they could either use by altering input variables, or decompose to examine the underlying workings (see Figure 5).

\section{[INSERT FIGURE 5 HERE]}

Finally, students could undertake Lunar lander game-making. They were given a basic version of the Lunar lander game in ToonTalk to modify and extend, posting their own versions on the WebReports site to share with others. Although students could examine our pre-built tools (for example the acceleration tool) or program their own variations in the previous activities, this was not required and the focus was more on setting and controlling variables. Our hope was that in building programs, the students would come to link more directly the motion of the lander with the underlying models that drove it.

\section{Students' background knowledge}

In reviewing the corpus of data gathered during the students' activities, we extracted instances and episodes where students' interactions, written productions or utterances opened a window on their thinking in relation to the issues we discussed earlier (e.g. variable confusion), and possible ways in which their interactions may have mediated their thinking. In the interviews we undertook before starting the activities, we again found that students typically held quite fuzzy intuitions about the idea of acceleration, 
Exploring the mathematics of motion through construction and collaboration (2006) Journal of Computer Assisted Learning, 22, pp114-136

especially when they attempted to link their intuitions with dimly-recalled school learning. For example, when asked to explain acceleration:

Adrian: Distance divided by time is speed. Isn't there something - speed divided by time? No.

Researcher: What's that?

Adrian: Oh no, that's - speed divided by time is distance. I don't know.

Researcher1: You have no idea? What did you say before? Just repeat that thing you said before about your definition of acceleration [Adrian had mentioned 'good' acceleration].

Adrian: Acceleration is how quickly something gets to its terminal velocity.

Researcher1: How quickly something gets to its terminal velocity?

Adrian: Or it's um, how quickly it gets to its top speed, how quickly it gets to a certain speed.

Researcher2: Again you said if it has good acceleration then?

Adrian: It gets to its top speed quicker.

Researcher2: So do you measure acceleration by good or bad, or can you measure it?

Adrian: In cars you want it good.

Researcher: In cars, you want it good. What does 'good' mean?

Edward: Quicker, the higher the acceleration the better the car.

Clearly Adrian had some knowledge about the relationship between distance, speed and time, but had difficulty in relating this to acceleration. We found generally that students initially thought of acceleration in terms of 'how quickly' or 'fast' something moves, or in terms of 'speeding up', but that they struggled to define it precisely as change in velocity over time, and did not consider that acceleration could also be 'slowing down'. This is not surprising, given the everyday meaning of the word 'acceleration' which is in many respects different from the scientific one - it is for example, measured in seconds (e.g. acceleration of 0-60 m.p.h in 6 seconds)!

In addition, we should state, without going into unnecessary detail, that the responses to the pre-activity questionnaire (see Appendix A) confirmed that students in both sites, understood graphs in ways that are well-represented in the literature. That is, all but six 
Exploring the mathematics of motion through construction and collaboration (2006) Journal of Computer Assisted Learning, 22, pp114-136

students exhibited both 'graph as picture' and 'variable confusion' errors. For example, in Question 2 most students selected A, B or E which describe an object moving or rolling 'down a hill' - a description clearly more consistent with interpreting the graph as a picture than an abstract representation. Similarly, in Question 4, most students at both sites chose $\mathrm{B}$, which would be the correct answer if the $\mathrm{y}$-axis represented velocity rather than position, an instance of 'variable confusion'. In fact, the Cypriot analysis showed that in general students' interpretations of the graphs were more consistent with velocity-time, regardless of what variable was actually represented on the y-axis.

\section{Some illustrative learning episodes}

We now present a sequence of five episodes that describe students' responses to the activities, and try to elaborate the ways in which their understandings of motion evolved. We only describe episodes involving students in London, although some of these were contingent on interactions with the Cypriot site. Our focus is tracing how they articulated and argued about relationships between the key variables and they were represented in different forms.

\section{Episode 1: Developing a language for units of velocity}

During the first session in London, two students were experimenting with moving objects around in ToonTalk using sensors. In ToonTalk, position is represented by the Right and $U p$ sensors, which are defined as both being 0 at the bottom left of the screen, and 1000 at the top right. A discussion ensued:

Researcher: What's the units of this velocity?

Adrian: One of these per second isn't it?

Researcher: Right, one screen unit per second.

Page 19 of 55 
Exploring the mathematics of motion through construction and collaboration (2006) Journal of Computer Assisted Learning, 22, pp114-136

Edward: Yeah, what is that?

Researcher: It's divided into 1000 so it's just a screen unit.

Edward: Pixels.

Researcher: Yeah if there were a 1000 pixels but its not exactly.

Adrian: Can we make a name for it? And then that can be the universal name for it...

Adrian: Whenever you go to a new school are you going to use the name 'Adwards'?

Researcher: Yeah, yeah, it's a new term now, it's an official term!

Edward: You have to! We'll put it on the website.

Adrian: Yeah let's put it on the website.

The two students then logged in to the WebReports site and published the report as shown in Figure 6.

\section{[INSERT FIGURE 6 HERE]}

This short (and unplanned) episode highlights several interesting points. The students had the good idea of inventing a unit for ToonTalk position. They encountered some initial difficulty in working out what the numbers on position sensors represented, both because the number of units per screen (1000) is arbitrary, and because they are screen relative rather than absolute units (i.e. scrolling the screen changes the sensor values). Their immediate reaction after their 'discovery' was to publish their findings on the WebReports site. Their behaviour shows they were very much aware of the community built up around the WebReports site, and that they wanted to contribute to this community and, in their words, 'stop international confusion'! It is also interesting how they based the name of the term on a contraction of their own two first names - it seems they wanted to be identified with its invention and subsequent use. Indeed, in further group discussions these two students continued to use the term 'adwards', although other group members seemed resistant to picking it up! 
Exploring the mathematics of motion through construction and collaboration (2006) Journal of Computer Assisted Learning, 22, pp114-136

\section{Episode 2: Learning from prediction by relating representations}

Students in London were in most cases able accurately to predict the shape of positiontime and velocity-time graphs after observing the behaviour of the cars in the Predicting graphs after observing motion activity. More interesting were the events where students incorrectly plotted the graphs, and had to debug their models. One case involved a car that started from zero velocity and then accelerated at a constant rate. Having watched the car, Lance sketched the speed-time graph shown in Figure 7.

\section{[INSERT FIGURE 7 HERE]}

He then re-ran the car model, captured the data and exported them to Excel to produce the graph. When he compared this to his prediction he immediately noticed the difference, and went on to sketch the correct line on his graph and noted that he had mistakenly drawn a position-time graph when he should have been plotting speed-time. He made exactly the same mistake a second time for another of the cars.

Students were asked to reflect on the activity in a group discussion at the end of the session:

Mike: You just have to get your mind around them. You have to understand why it's doing it. Lance: I think you need to spend longer looking exactly at like, what you're plotting.

$\cdots$

Researcher: What were the kind of mistakes you made?

Adrian: Getting carried away.

Mike: Replacing 'right speed' for 'right'.

Lance: Not plotting the right thing - not thinking about what you are plotting.

Mike used ToonTalk language (referring to 'right speed' and 'right' sensors) to explain that he also mistakenly plotted a position-time graph when he should have plotted speed- 
Exploring the mathematics of motion through construction and collaboration (2006) Journal of Computer Assisted Learning, 22, pp114-136

time. Interestingly, Lance twice pointed out the necessity to 'think about what you are plotting', obviously in reaction to the mistakes he made. These mistakes were examples of the well-known and expected 'variable confusion' - but importantly, the activities allowed the students to reflect on their own mistakes, and to modify their understandings and future approach.

Mike and Adrian both made an interesting mistake when plotting the position-time graph for a car that accelerated to a given speed (200), then continued traveling at that speed, as highlighted in Figure 8. In both students' predictions, there was a discontinuity between the acceleration part of the graph (curve) and the constant speed (straight line).

\section{[INSERT FIGURE 8 HERE]}

Mike was asked to explain the difference between his prediction and the graph plotted from the data:

Researcher: Ok, so explain to me what the car did in words.

Mike: The car accelerated until it got to 200 and then it just stayed at 200.

Researcher: Ok, how did you draw that?

Mike: I drew some weird 'j' really. I drew that it would accelerate...

Researcher: So when it accelerates, that means what? It's a...

Mike: It will be a curve on the position but then when it stops accelerating it will actually decrease but it didn't. I don't know, that was wrong - I didn’t draw it right.

Researcher: Why do you think it did it like this?

Mike: Because if it did it like that, it would decrease, but it didn't, it stayed the same. It's like a curve or a circle, and it's like a tangent because it stops accelerating.

Researcher: Ah... you said it's like a curve or a circle and then the line that comes off is like a tangent?

Mike: Yeah.

Researcher: Ok, so why would it be like a tangent?

Mike: Because it would just go off - because it stops accelerating which means it stops curving and it goes at a straight line. 
Exploring the mathematics of motion through construction and collaboration (2006) Journal of Computer Assisted Learning, 22, pp114-136

It is noticeable that Mike was very clear about how the acceleration corresponds to a curve on the position-time graph, and constant speed to a straight line. Mike reasoned that the speed does not decrease at the transition to constant speed, and therefore the graph should not show such a decrease in speed. Note that he also correctly identified the straight line as being a tangent to the curve.

Adrian's prediction graph was similar to Mike's, and when asked specifically about the discontinuity, he reasoned that the graph should be smooth because there is no corresponding discontinuity in the speed of the car:

Adrian: Because... it doesn't speed and stop and then find a new speed and go up.

Lance's prediction for the graph was correct, although it is not clear whether this is because he had already seen Mike's prediction. Again, he reasoned about the shape of the graph, and when asked about the prediction graph that Mike had drawn:

Lance: Yeah, course it was wrong because otherwise it would have to change speed suddenly.

One interpretation of these three students' reasoning is that they were mindful of the ToonTalk robots on the back of the cars that controlled their movement. They may have realised that the robot responsible for the acceleration stopped when the speed 200 was reached. For example, Adrian may have held the emerging understanding that an additional robot would be required for the car to 'find a new speed'. This interpretation is supported by Lance, who describes below his systematic approach to observation - first he watched the actual motion of the car and then the ToonTalk sensors. Note that he also realized there must be some logic to stop the car decelerating when it reaches speed 0 , 
Exploring the mathematics of motion through construction and collaboration (2006) Journal of Computer Assisted Learning, 22, pp114-136

and following this discussion he went on to 'flip' the cars and examine the programmed ToonTalk robots on the back of them:

\footnotetext{
Researcher: So when you're watching it, like you watched this a couple of times first, don't you, before your plot it? What are you actually watching?

Lance: I wanted to see what the car does with the value 200 because you've already given it the value 200 so it must do something important.

Researcher: What things are you watching? Are you watching the car?

Lance: I'm watching the car to see it first time and then the second time I watch the numbers. So that time I saw that it was decreasing acceleration because it went from 200 to 0 . But then there must be something saying that when it gets to 0 stop, otherwise it just keeps going.
}

We see that the explicit distinction between model, data and graph that we outlined earlier, may have played an important role in Lance's insight.

\section{Episode 3: Guess my Graph Challenge - articulating variants and invariants}

Five students in London and 20 in Cyprus participated in the Guess my graph challenge.

There were a total of 13 challenges posted: seven from Cypriot students, three from students in London, and three from researchers in London. Nine out of these 13 challenges were responded to via the WebReports comment mechanism (significantly more than in other activities); with a total of 86 comments being posted, 48 of which were responses by students that included an Excel graph attempting to solve the challenge.

An analysis of the comment thread length - that is the number of comments in a particular discussion - shows that the interactions were, for the most part, limited to short exchanges. Figure 9 shows that most challenges set by students had only one response, which in most cases was a graph solving the challenge, possibly with an accompanying 
Exploring the mathematics of motion through construction and collaboration (2006) Journal of Computer Assisted Learning, 22, pp114-136

explanation of the ToonTalk sensor values. Challenges set by researchers in comparison had comments with a minimum thread length of two - this is because the researchers made a conscious effort to reply to all responses to their challenges, typically supporting the responder or asking for clarification, but more often than not this was where the interaction ended. In summary, there was significant cross-site activity on the WebReports system in the Guess my graph challenge. However, the exchanges were short and generally consisted only of graphs - the end products of the modelling activity. As such, they served more as a motivation for students than genuine collaborative knowledge building, which occurred much more within sites in the classroom.

\section{[INSERT FIGURE 9 HERE]}

We now examine some of the challenge-responses in more detail. During a full-day workshop, students in London were set the task of responding to two specific Guess my Graph challenges posted by Cypriot students. The first of these challenges is shown in Figure 10. Students were split into three groups (two pairs, one group of three), and were instructed to post their responses on the WebReports site before a group presentation and discussion was to be held.

\section{[INSERT FIGURE 10 HERE]}

Two pairs successfully responded to the challenge, posting both their graphs and explanations of the process they followed, as the example in Figure 11 shows. Both responses acknowledged the relationship between initial speed and acceleration, the sign of these variables and the relationship to time. 
Exploring the mathematics of motion through construction and collaboration (2006) Journal of Computer Assisted Learning, 22, pp114-136

\section{[INSERT FIGURE 11 HERE]}

The third response is perhaps the most interesting (see Figure 12). Of particular note is that the graph is the same 'shape' but has different actual values to the challenge, due to the fact that it starts at position 1000 rather than 500, something the students note themselves in their report. When presenting the answer to the group, Andy explains:

Andy: So we set the initial up position as 1000 instead of 500 and we didn't actually think it made a difference and also when they, when Cyprus replied to some of ours they...

Researcher: They didn't - what did the Cyprus people?

Andy: They didn't use the same numbers.

What Andy is referring to here, is that the Cypriot students had previously responded to the challenge that he had set, and their graphs had not used the same numbers as his. In fact, Andy had 11 responses to his challenge, all of which had different scales on either xaxis (position) or y-axis (time). In a sense, Andy had adopted a standard or rule based on his experience in the 'guess my graph community' - a standard that was not necessarily shared by other students however:

Mike: It's just that you doubled the amount on the y-axis, but you didn't double the amount on the $\mathrm{x}$-axis, so really you didn't use the right thing. You didn't put in the right thing.

Lance: Yeah, basically all your values have changed.

Mike: It should have hit down - you got the right idea but it isn't actually the right graph.

Peter: You've slowed it down.

Andy: It's the right graph, it does the same thing.

Mike: If you used what they used in your... thing... in your lunar lander...it should've -

Alan: It's not mathematically similar.

Lance: Exactly, if it's not mathematically similar then it's wrong.

Adrian: It is mathematically similar it's just not exactly similar.

Lance: No no it isn't.

Mike It should have doubled the distance and doubled the time.

Researcher: [...] You should have done what sorry?

Mike: Um, if you doubled the distance - 
Exploring the mathematics of motion through construction and collaboration (2006) Journal of Computer Assisted Learning, 22, pp114-136

Andy: But um we, didn't actually think that making it exactly the same width or height or whatever actually made the graph wrong or right. If it does the same thing as the other graph, if it goes in the same pattern...

Researcher: Yes, I have another question here?

Peter: It does vaguely - well not vaguely but - it does a similar thing, but its half the speed at which it does it -

Mike No it's double the speed.

Peter: Double the speed, yeah.

The idea of mathematical similarity emerged, and students were divided over whether the response should be considered mathematically similar or not: the extent to which students were committed to their arguments and engaged in the discussion is hard to capture in the transcript - it is difficult to imagine such a passionate debate taking place during a typical mathematics class concerning the nature of mathematical invariants! Indeed, in a mathematical sense the graphs are similar - both being parabolas - but as Lance points out the actual values are different between the graphs (apart from when $\mathrm{y}=0$ ) so the underlying motion was different. This is a deep mathematical idea, and one that arose spontaneously as a result of the structure of the activities. Also of interest was that the students used the physical meaning of the graph as a criterion for comparison, for example Peter stating that it is at 'double the speed'.

[INSERT FIGURE 12 HERE]

\section{Episode 4: Articulating relationships in matching different descriptions}

Students in London were divided into two groups and set the task of matching narrative, ToonTalk sensor, position-time graph and velocity-time graph representations of the same motion event. Interestingly, both groups chose to start with the narrative description 
Exploring the mathematics of motion through construction and collaboration (2006) Journal of Computer Assisted Learning, 22, pp114-136

cards - perhaps this is not surprising given that it is arguably the most natural or least abstract representation. One group of three students started with the card: The lander starts at position 0, and moves up at a decreasing speed. After 15 seconds it reaches its peak height and moves down at an increasing speed. Their discussion:

\footnotetext{
Alan: Its starts at zero - so let's take all the ones out that don't start at zero.

This short transcript contains many interesting events, and is typical of the conversations from the two groups. Students used the process of elimination to discount options. For example, Alan suggested the removal of all cards that do not start at zero. In general, students used the starting points extensively for this purpose. This type of reasoning is more about the task itself than understanding of graphs per se. There was also evidence of students reasoning about the relationship between the kinematics variables. For example, Andy correctly determined that the initial up speed must be positive and the acceleration negative. Students reasoned about the relationships between the different representations: Andy observed that the initial speed value as represented by the ToonTalk sensor should match the initial value of the velocity-time graph. It was evident 
Exploring the mathematics of motion through construction and collaboration (2006) Journal of Computer Assisted Learning, 22, pp114-136

that the task was successful in getting the students to collaborate and share knowledge they each contributed different ideas, asked questions, and corrected one another - and we may note once more the extent to which students were committed and motivated to work on the mathematical dimensions of the task in order to achieve their intended outcomes.

\section{Episode 5: Building the lunar lander game}

Students were first shown an online 'Flash' version of the lunar lander game, before being shown the simplified ToonTalk version. They were then given the opportunity to extend and modify the ToonTalk version as they desired. Students came up with a number of interesting ideas, and with help from the researchers, implemented a number of them.

Alan, Lance and Adrian decided they wanted to add a fuel feature (this is a key component of the Flash version of the game, but was deliberately omitted from the ToonTalk version). First, they needed to decide what fuel consumption should link to. Lance's initial suggestion was to make it time-based, i.e. reduce fuel by a fixed amount each time unit. However, the students then realized that if the lander was free-falling or moving at constant speed, fuel should remain fixed. This observation illustrates a surprisingly robust understanding of what is special about constant velocity, acceleration, gravity and so on. The group then determined they wanted a counter for fuel, which should decrease when the boost is on. They also needed to reset the position of the lunar lander when the fuel went below zero. Programming this is not trivial, requiring a 'team' of robots in ToonTalk, but with help from the researchers the students were successful, as shown in Figure 13. 
Exploring the mathematics of motion through construction and collaboration (2006) Journal of Computer Assisted Learning, 22, pp114-136

\section{[INSERT FIGURE 13 HERE]}

After adding the fuel feature, the three students continued to work independently. In particular, Lance was highly engaged in this activity; the next change he decided upon was to reduce the speed sensitivity of the landing pad, in order to make it easier to land. This involved finding the appropriate robot and changing a value in its input box (i.e. changing a parameter). Lance also wanted the lander to reset position and score if it went off the edge of the background picture. He realised that he could reuse the existing landing pads for this purpose, by modifying their size and placing them around the edges of the background picture. He also changed the 'score' variable in the robot's box to ' $=0$ ' so that instead of having a score added on successful landing, the score would be reset to zero if the lander hit the edge of the picture. Lance also wanted to give the rocket more fuel. On the first attempt he simply increased the fuel number pad on the picture, but then realised that a robot was programmed to reset the fuel to a certain number when it ran out. He located this robot, and trained a replacement robot to reset the fuel value to a higher number.

In summary, in a relatively short space of time, the students completed some interesting modifications to the game. In some cases the changes involved simple modification of parameters, in others reusing and modifying existing modules (e.g. the landing pads for picture edge detection) and in other cases new robots were programmed from scratch. In the process, they engaged with a number of new programming concepts (e.g. teams of robots). Some of the modified games were posted on the WebReports site. It was evident that students were excited and engaged with designing and building their own games. 
Exploring the mathematics of motion through construction and collaboration (2006) Journal of Computer Assisted Learning, 22, pp114-136

\section{Summary and concluding remarks}

We now turn to the task of attempting to map the relationships between the trajectory of the students' thinking - how their thinking about motion evolved - and what they actually did in the after-school workshops in terms of computational interactions.

Before we do so, let us begin with the simplest, and crudest, observation, derived from the post-activity questionnaire, which involved students completing the same written questionnaire as given in the pre-activity. We make no particular claims concerning the results of this assessment: its main rational was, as we pointed out earlier, to indicate avenues for further discussion or for investigation in interviews. Nevertheless, some of the results are worth noting. Of the four students in London that regularly attended sessions, three increased their scores after activities. The total correct answers increased from 8 out of 28 (29\%) pre-activity to 14 out of 28 (50\%) post-activity. In Cyprus, the total correct answers from 14 students increased from 18 out of 98 (18\%) pre-activity to 30 out of $98(30 \%)$ post-activity.

While this is encouraging, we were much more interested in looking at the quality of students' answers. When we look across the learning episodes illustrated in the preceding examples, we can discern several trends. First, we consider the question of 'variable confusion'. At one level, this is an unremarkable phenomenon: students do not pay enough attention to the scale, are unsure what the precise definition of 'velocity' or 'acceleration' are - there are many possibilities. But at a deeper level, we see here an example of fragmented knowledge: if we instead consider what students do know, we 
Exploring the mathematics of motion through construction and collaboration (2006) Journal of Computer Assisted Learning, 22, pp114-136

find that they have a wide range of understandings, some of which are valid, some have limited (and over-extended) validity, and some, of course, are just plain wrong.

In this scenario, learning can be said to occur when new understandings are developed, existing understandings linked to others, or the range of application of a knowledge element is refined: or when existing incorrect intuitions are indeed enhanced (or replaced) by new, correct knowledge. Considered from this perspective, we saw in the episodes some evidence that learning had occurred.

For example, when reflecting on their work in the Predicting graphs from motion activity, we saw how students highlighted the necessity to pay attention to the variables being plotted. We conjecture that this flowed from the constructive nature of the tasks with which we presented the students ${ }^{9}$. This was evident in Matching different descriptions: students made connections between the kinematics graphs on the basis of 'points of change', and reasoned about how the relationship between initial speed and acceleration gave rise to graphs of particular shapes. More generally, most students seem to have learnt (we did not set out explicitly to teach them) that constant acceleration corresponds to a curve on a position-time graph and a straight line on a velocity-time graph.

We were impressed at the ways in which the students were able to reason about the meaning of the graphs in the real world. For example, when considering the discontinuity mistakenly plotted in the Predicting graphs from motion activity, we saw how students

\footnotetext{
${ }^{9}$ This stands in contrast to the 'look and see' style of software, in which students can at best set the values of certain parameters, but are unable to exploit the technology to build (and therefore understand) the relationships between them. See, for example, Trowbridge (1996).
} 
Exploring the mathematics of motion through construction and collaboration (2006) Journal of Computer Assisted Learning, 22, pp114-136

explained the error by reasoning about the motion of the car, its speed just prior to and just after the point of discontinuity on the graph. Similarly, in the debate about 'mathematical similarity' that arose while solving a Guess my graph challenge, students reasoned that although the response graph was similar in shape, it was not a correct answer because the speed at which the lander was travelling was different. This knack of thinking through the graph entails not only realising that a kinematics graph is an abstract representation of a motion event, but being able to reason about the types of motion that the graph describes.

Our claim, therefore, is that the act of construction through the program is the crucial link between the representations. Students were not simply watching 'multiple representations' - graphs, data, moving objects - they were involved in constructing relationships between them, and so - at least we conjecture - constructing corresponding cognitive relationships. Unless the variables were carefully differentiated, and the linkages between them made explicit, the models simply would not run, or at least would not run in any useful way. The act of construction provided the coordination between representations (see Sacristán \& Noss, in press, for more on this notion of coordination), and this in turn, afforded the possibility for students to coordinate their own, sometimes conflicting, intuitions.

Furthermore, we argue that the formal expression of the relationships as a program, was constitutive of meaning construction (a contrast with the more traditional approach which regards formalisation as the means to express an already-understood relation. For example, throughout the initial activities, we saw that students viewed the relationship 
Exploring the mathematics of motion through construction and collaboration (2006) Journal of Computer Assisted Learning, 22, pp114-136

between initial velocity and acceleration as challenging and counter-intuitive. All of the London students supposed - in some form or another - that if an object that goes up, reaches a maximum, and then moves downwards (a parabola on a position-time graph), its motion is best described as somehow composed of two parts - an up part and a down part. This sort of motion can be modelled in ToonTalk by setting a positive initial velocity and a negative acceleration (this is akin to throwing a ball in the air with an initial upwards impulse and the downward force due to gravity). A key insight, made by all of the London students in some form or another, derived from realising that the value of acceleration does not change and the 'two parts' of the motion do not need to be programmed separately. If a robot did not 'change' a value, then that value could not change; and conversely, if the value stayed invariant, no robot could be acting upon it.

This crucial aspect of formalisation was strengthened and extended by the collaborative dimension, exemplified in the Guess my Robot activity. Students were clearly motivated and engaged in the activity, and it proved successful in motivating significant cross-site communication between students and resulted in animated face-to-face discussion and debate. However, cross-site collaboration leading to enhanced motivation is the only the most obvious part of the picture. More important was that - through sharing models - the role of formalisation was evident to students - without formalisation of the models, there was effectively no 'game'. We remark that it is a challenge to conjure up activities in mathematical classrooms where the role of formalisation is both 'obvious' and 'fun'.

It is appropriate to draw attention to two limitations of our study. It was evident over the course of the activities that the students became highly proficient at using the relevant 
Exploring the mathematics of motion through construction and collaboration (2006) Journal of Computer Assisted Learning, 22, pp114-136

tools as they acquired greater expertise with the affordances of the system. For example, all the London students easily switched between controlling and experimenting in ToonTalk to analysing data and plotting graphs in Excel, expertly reporting their findings including graphs and ToonTalk models on the WebReports system. During Lunar lander game-making, students modified parameters, re-used existing programs, and programmed robots from scratch in order to extend the provided game. The first limitation arises from recognising that students in London had previously completed number sequences activities, while many of the Cypriot students were returning to WebLabs for a second year. We therefore cannot overestimate the amount of time needed for this kind of fluent use of a large open toolset. Second, we should be realistic about our own role as participant observers: we cannot claim that our findings generalise, in the sense that any of the elements we designed could be expected to 'work' without expert intervention. Our claim is not that we have designed a system that 'works' with (general) students and (general) teachers: only that a system such as the one designed has certain affordances for learning, particular elements that map to understanding certain phenomena connected to motion.

We conclude with a brief glimpse of the data collected in stimulated-recall interviews conducted after the completion of the activities, in which we asked students to explain their choices on the post-activity questionnaire. We choose a couple of suggestive extracts that support the claims above.

Interestingly, all but one of the students changed their answers while justifying them, highlighting the relative instability of their responses. The process of explaining their 
Exploring the mathematics of motion through construction and collaboration (2006) Journal of Computer Assisted Learning, 22, pp114-136

reasoning affected their answers, which is not altogether surprising, and points to the relative fragility of their knowledge. At the end of each interview, the researcher asked the student, why he thought he had improved on the test. Adrian responded:

Adrian: Yeah, it clears it up, so...Especially things like this where it's saying you have to imagine what the graph would look like, like if you think about putting it into ToonTalk, what would happen then, and then putting the graph in.

Researcher: OK, so do you actually do that, like when you saw this description, did you think about what it would look like in ToonTalk, or?

Adrian: Not really in ToonTalk as such, but that kind of helped us because of just, just doing it, because when we had those worksheets about knowing how to type it in, and then imagining what the sketch of the graph would look like, it's almost exactly the same.

It seems that Adrian is claiming that his ability to predict what a graph should look like from a narrative description improved as a result of his experience with producing graphs in ToonTalk (in the last line he specifically refers to the worksheets in the Predicting graphs from motion activity). Similarly, Lance claimed that being able actually to observe an object moving, and then see the resulting graph was more helpful than just being shown a graph and then told what the object did:

Lance: So rather than just like looking at the graph and then being told what the object's doing it's easier to actually see the object do it, and then look at the graph.

Researcher: Right, so you mean -

Lance: 'Cause then you see exactly what it does. It's much easier than if someone just tells you 'this graph means that it's decreasing in acceleration or whatever'.

Mike pointed out that although he had a concept of what acceleration meant he did not know what it looked like on a (kinematics) graph. Like the other students, he singled out using the acceleration tool to produce the graphs in Excel from the ToonTalk data as having helped him to answer the questions better the second time: 
Exploring the mathematics of motion through construction and collaboration (2006) Journal of Computer Assisted Learning, 22, pp114-136

Mike: Knowing what acceleration is and how it corresponds, how it relates to just... the constant speed, the velocity, and how, it's just position. Yeah, I didn't really know at all what acceleration looked like on a graph.

Researcher: You didn't know what acceleration meant, did you say?

Mike: No, I knew it meant you go faster, but I didn't know at all what it would look like on a graph.

Researcher: Right, what it would look like on a graph, ok, so what - were there any, like, of the things we did in particular that you think helped, or just like everything, or...?

Mike: Like with the lunar lander, when you plot the graph and you change the acceleration that's like, yeah, just doing like one or two of those graphs, and that probably changed about most of the answers that I got right, they were wrong before and that I turned to get right. Yeah, just using the acceleration and lunar lander has probably helped.

\section{A concluding remark}

Our final point returns us to the centrality of constructing relationships in the design of our system. We have seen how students came to see through the graphs to the relationships they had built and observed, coordinating the disparate knowledge elements with which they began. We attribute this in large measure to the scope that the system afforded for building on existing knowledge through construction, and for viewing as a process the results of choices for relationships and parameter values. It also supports the claim, referred to earlier, of Arzarello \& Robutti (2004) that students can understand distance-time and velocity-time relationships and their graphs provided they can build and share their conceptual genesis.

\section{References}

Arzarello, F., \& Robutti, O. (2004). Approaching functions through motion experiments. Educational Studies in Mathematics, 57 (3), 305-308. 
Exploring the mathematics of motion through construction and collaboration (2006) Journal of Computer Assisted Learning, 22, pp114-136

Beichner, R.J. (1990). The effect of simultaneous motion presentation and graph generation in a kinematics lab. Journal of Research in Science Teaching, 27, 803815.

Beichner, R.J. (1994). Testing student interpretation of kinematics graphs. Am. J. Phys. $62(8), 750-755$.

Brasell, H. (1987). The effect of real-time laboratory graphing on learning graphic representations of distance and velocity. Journal of Research in Science Teaching, $24,385-395$.

Brungardt, J., \& Zollman, D. A. (1995). The influence of interactive videodisc instruction using simultaneous-time analysis on kinematics graphing skills of high school physics students. Journal of Research in Science Teaching, 32, 855-869.

Cobb, P., Confrey, J., diSessa, A., Lehrer, R. and Schauble, L. (2003). Design Experiments in Educational Research. Educational Researcher, Vol. 32, No. 1, pp. 9-13

Confrey, J. (1990). A review of the research on student conceptions in mathematics, science and programming. Review of Research in Education, 16, 3-47.

Cypher, A. (ed.), (1993). Watch What I Do: programming by demonstration. Cambridge, MA: MIT Press.

diSessa, A. A. (1988). Knowledge in pieces. In G. Forman \& P. B. Pufall (Eds.), Constructivism in the computer age (pp. 49-70). Hillsdale, NJ: Lawrence Erlbaum Associates. 
Exploring the mathematics of motion through construction and collaboration (2006) Journal of Computer Assisted Learning, 22, pp114-136

diSessa, A., Hammer, D., Sherin, B. \& Kolpakowski, T., (1991). Inventing graphing: Meta-representational expertise in children. Journal of Mathematical Behavior, $10,117-160$.

diSessa, A. (1993). Towards an epistemology of physics. Cognition and Instruction, 10, 105-225.

Harel, I., \& Papert, S. (eds.). (1991). Constructionism. Norwood, NJ: Ablex Publishing Corporation.

Janvier, C. (1981). Use of situations in mathematics education. Educational Studies in Mathematics, 12, 113-122.

Kahn, K. (1996) ToonTalk - an animated programming environment for children. Journal of Visual Languages and Computing 7, 197-217.

Kahn, K. (1999) From prolog to Zelda to ToonTalk. In D. De Schreye (Ed.) Proceedings of the International Conference on Logic Programming, 1999 (pp. 67-78). Cambridge, MA: MIT Press.

Hegedus S. J., \& Kaput, J. J. (2004). An introduction to the profound potential of connected algebra activities: Issues of representation, engagement and pedagogy. In Proceedings of the 28th Conference of the International Group for the Psychology of Mathematics Education (Vol. 3, pp. 129-136). Bergen, Norway.

Hoyles, C. \& Noss, R. (in press) Exploring Mathematics through Construction and Collaboration. In K.R. Sawyer (Ed) Cambridge handbook of the Learning Sciences. Cambridge: CUP. 
Exploring the mathematics of motion through construction and collaboration (2006) Journal of Computer Assisted Learning, 22, pp114-136

McCloskey, M. (1983). Naïve theories of motion. In D. Gentner \& A. Stevens (Eds.), Mental models (pp. 299-324). Hillsdale, NJ: Lawrence Erlbaum Associates.

McDermott, L. C. (1984). Research in conceptual understanding of mechanics. Physics Today, 37, 23-32.

Mor, Y., Hoyles, C., Kahn, K., Noss, R., \& Simpson, G. (2004). Thinking in Progress Micromath, 20 (2), 17-23.

Mor, Y., Tholander, J., \& Holmberg, J. (In Press). Designing for cross-cultural webbased knowledge building. Proceedings of CSCL '05: The Tenth International Conference on Computer Support for Collaborative Learning.

McDermott L.C., Rosenquist, M. L., \& van Zee, E. H. (1987). Student difficulties in connecting graphs and physics: Examples from kinematics. American Journal of Physics, 55, 503-513.

Nemirovsky, R., Tierney, C., and Wright, T. (1998). Body Motion and Graphing. Cognition and Instruction, 16(2), $119-172$.

Noss, R., \& Hoyles, C. (1996). Windows on Mathematical Meanings: Learning Cultures and Computers. Dordrecht: Kluwer.

Sacristán, A. \& Noss, R. (in press). Computational Construction as a means to Coordinate Representations of Infinity

Simpson, G., Hoyles, C., \& Noss, R. (2005). Designing a programming-based approach for modelling scientific phenomena. Journal of Computer Assisted Learning, 21 (2), 143-158. 
Exploring the mathematics of motion through construction and collaboration (2006) Journal of Computer Assisted Learning, 22, pp114-136

Thompson, P. W. (1994). The development of the concept of speed and its relationship to concepts of rate. In G. Harel \& J. Confrey (Eds.), The development of multiplicative reasoning in the learning of mathematics (pp. 181-234). Albany, NY: SUNY Press.

Trowbridge, D (1996). Graphs and Tracks. Physics Academic Software Publishing Organization. (http://webassign.net/pas/graphs_and_tracks/gandt.html) 
Exploring the mathematics of motion through construction and collaboration (2006) Journal of Computer Assisted Learning, 22, pp114-136

\section{Figures}

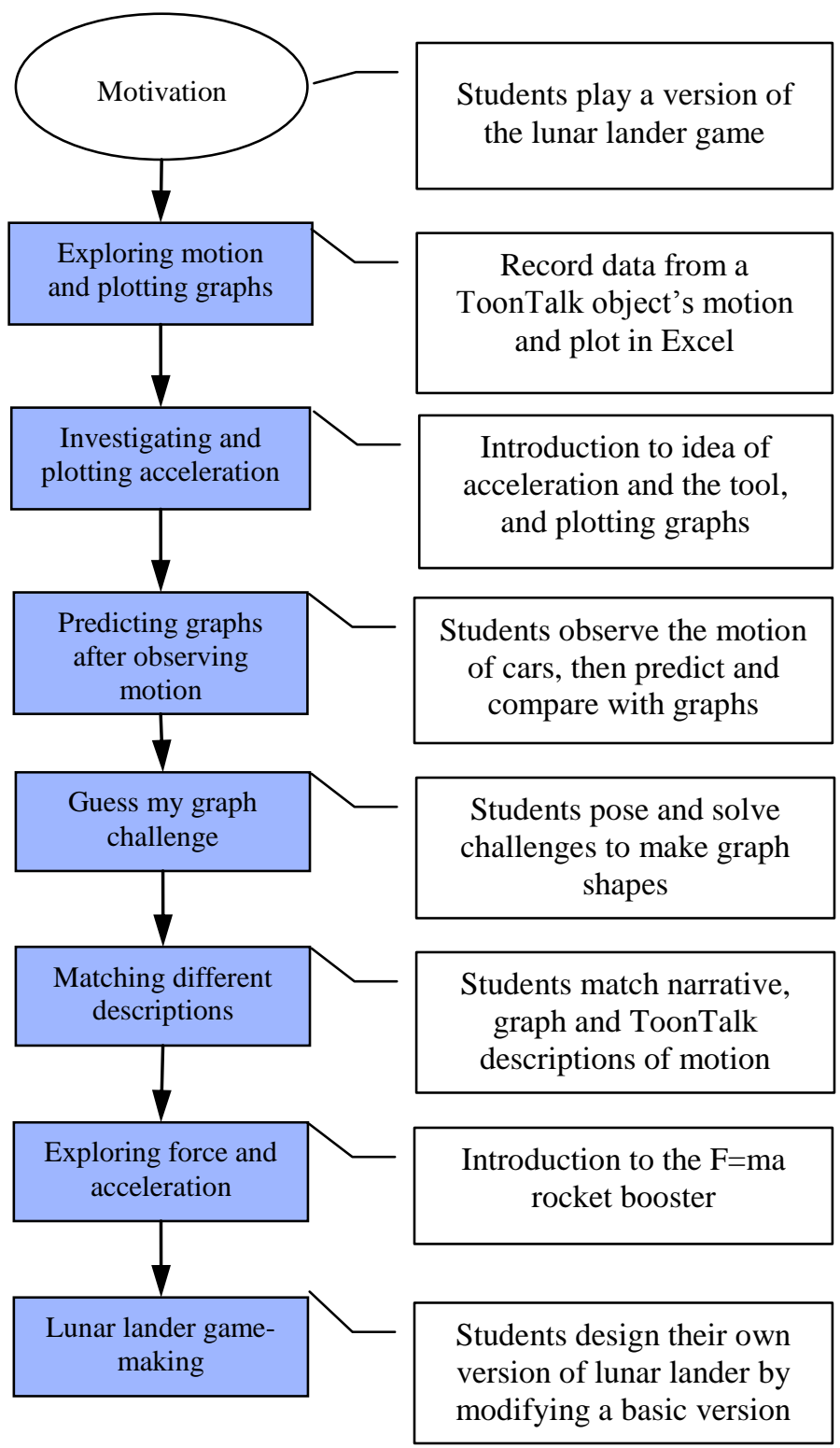

Figure 1. 
Exploring the mathematics of motion through construction and collaboration (2006) Journal of Computer Assisted Learning, 22, pp114-136

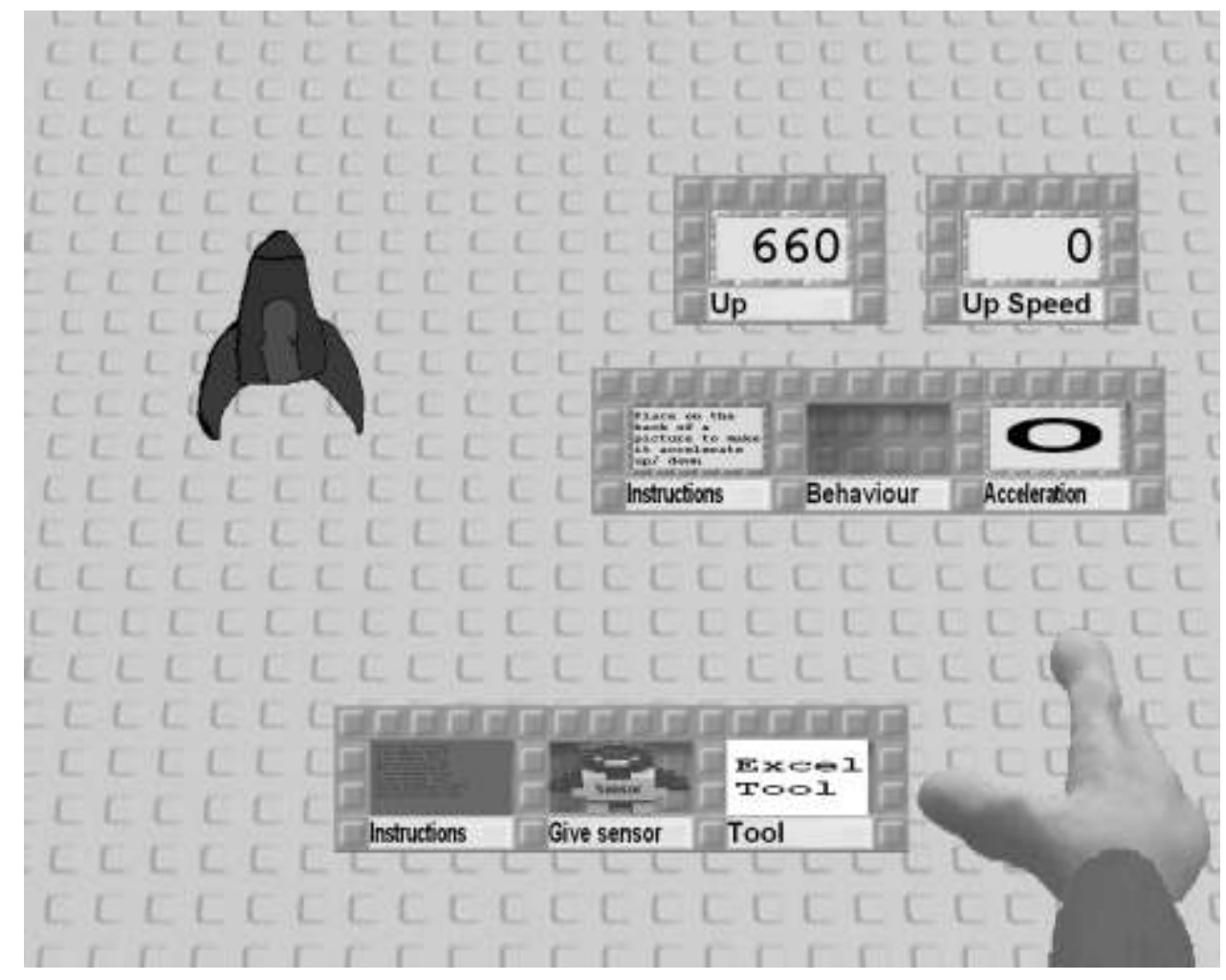

Figure 2.

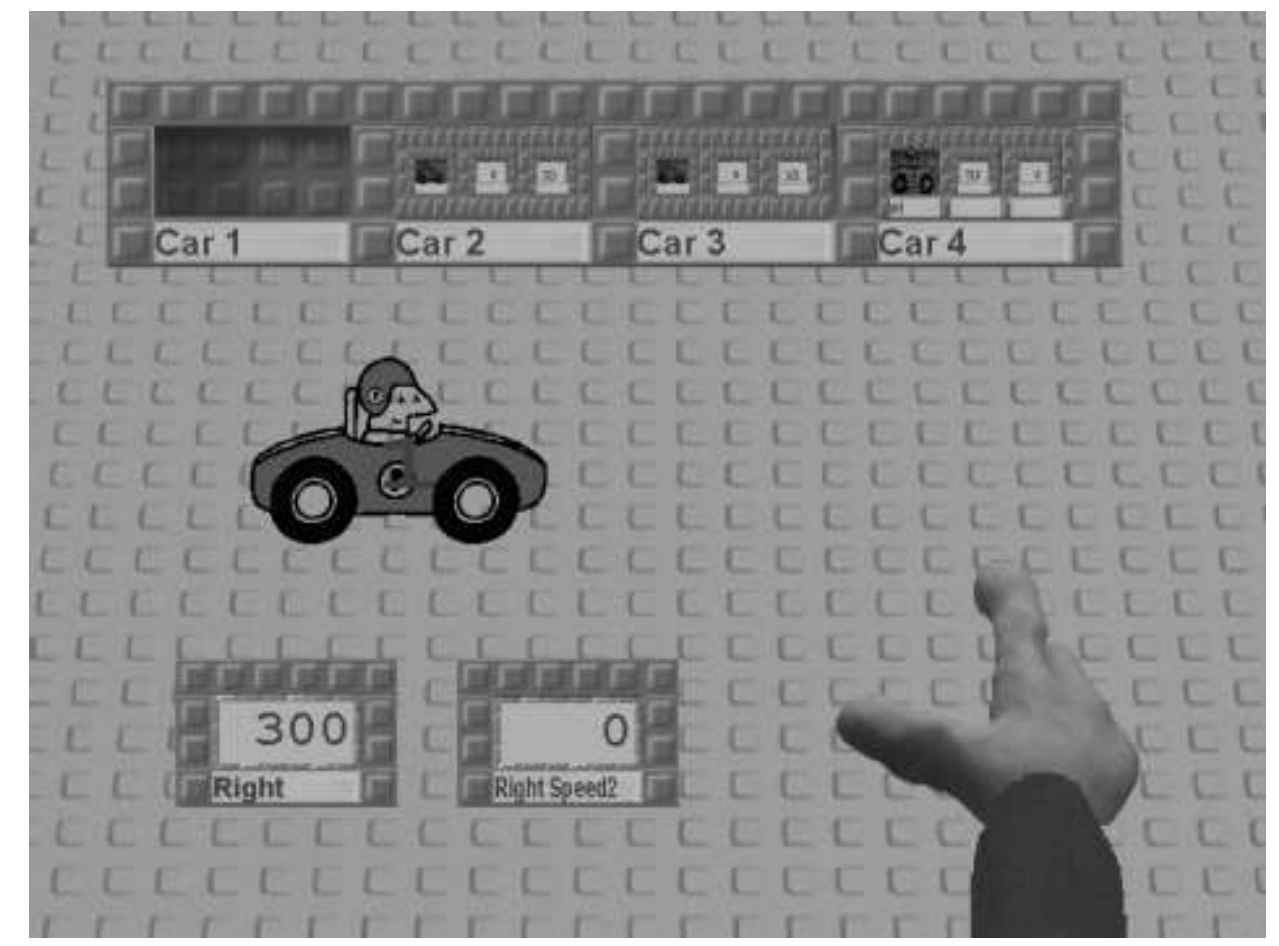

Figure 3. 
Exploring the mathematics of motion through construction and collaboration (2006) Journal of Computer Assisted Learning, 22, pp114-136

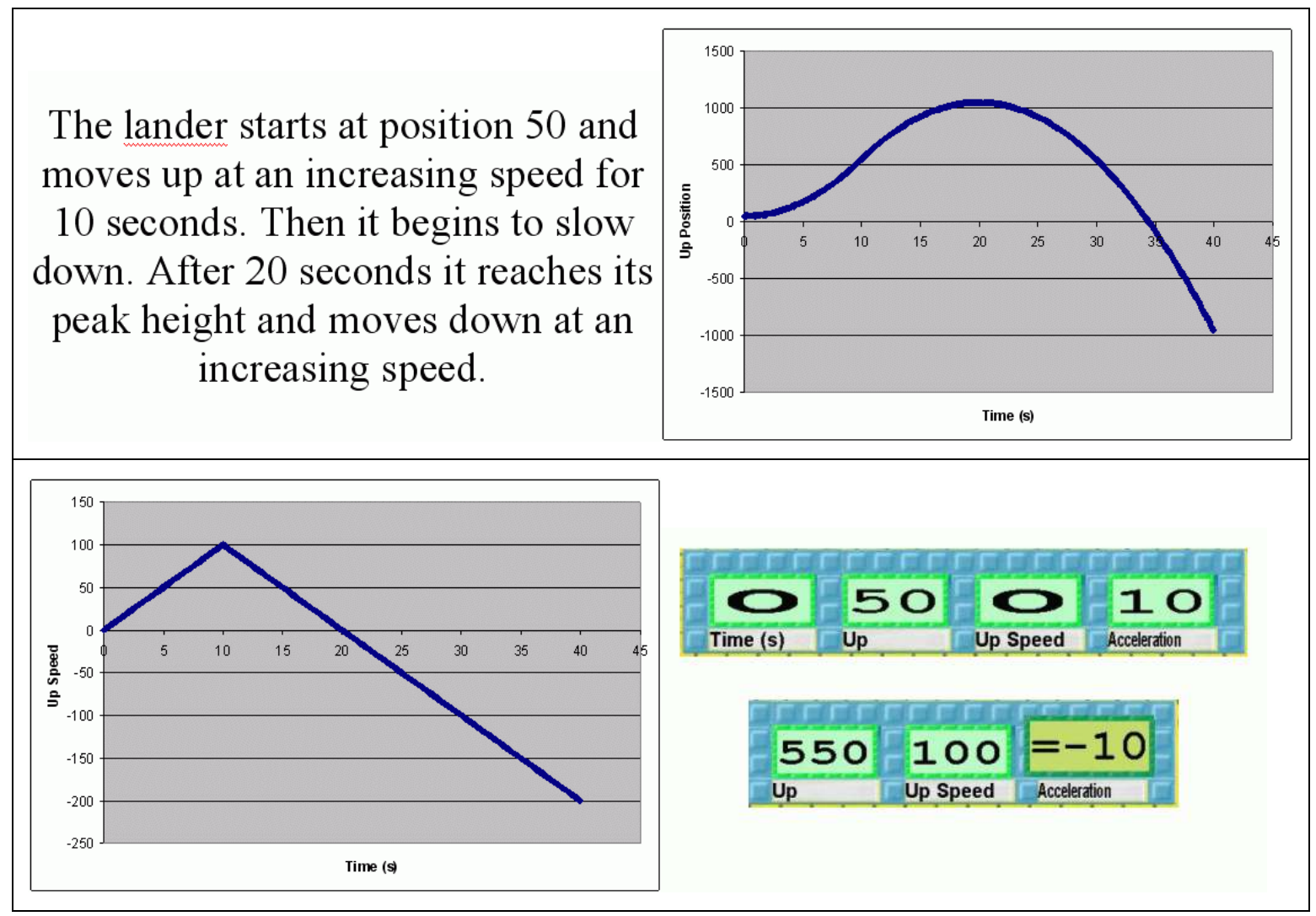

Figure 4.

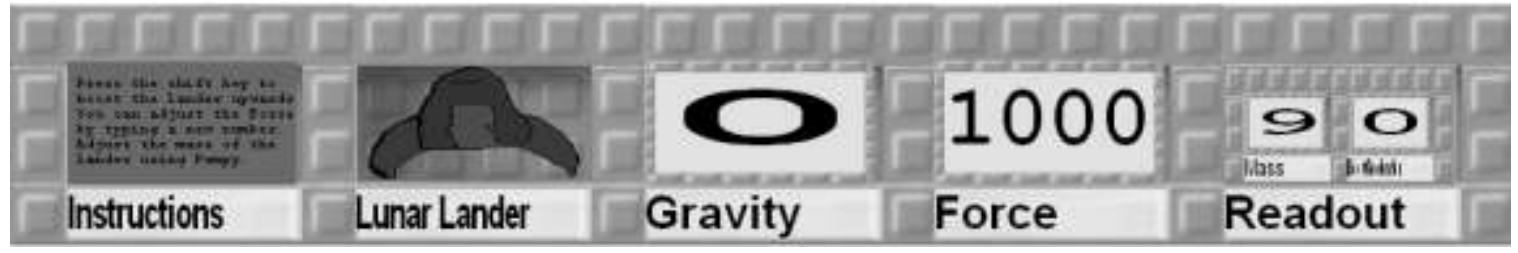

Figure 5.

We decided when doing Lunar Landing, that when describing the position of the picture or space ship's position is very complicated. Therefore, from now on the word used for the pictures position is ADWARD'S across or ADWARDS up. WE are asking you to please always use this term to stop international confusion. There are 1000 Adwards accross and 1000Adwards up in evfery screen. You can find this position by looking in the book when the picture is flipped. Thankyou.

P.S The name ADWARDS comes from the 2 boys that created this unit: ADrian and edWARD.

Figure 6. 
Exploring the mathematics of motion through construction and collaboration (2006) Journal of Computer Assisted Learning, 22, pp114-136

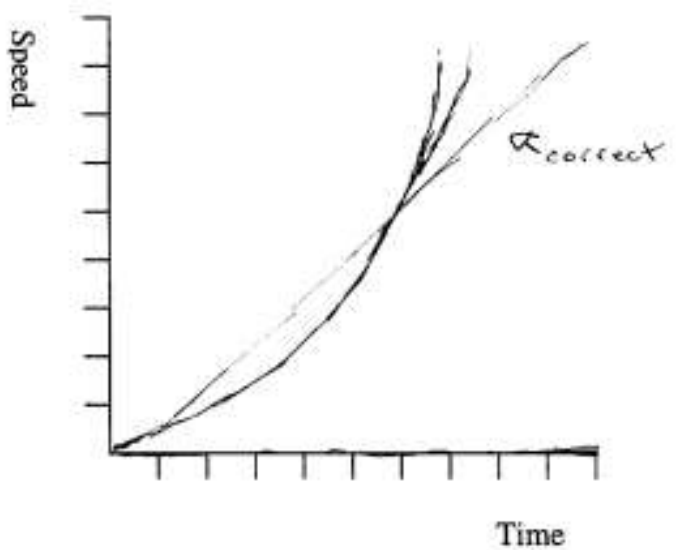

7. Now plot the graph in EXCEL, and compare it to the graph you predicted above. Examine both graphs and note similarities and differences.

Similarities:

1...... None.

3.

4.

Differences:

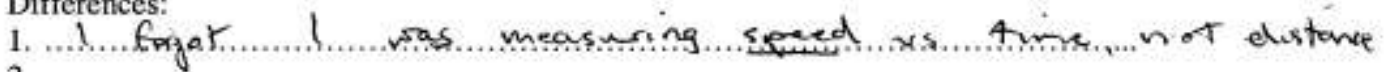

2.

3.

4.

Figure 7.

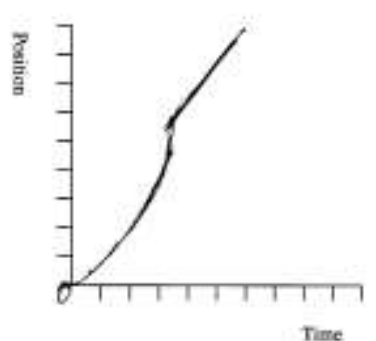

7. Now plot the gragh in EXCE2, and convare it to the graph you prodicasd shove. Examine both graphs and tote similarities and differences.

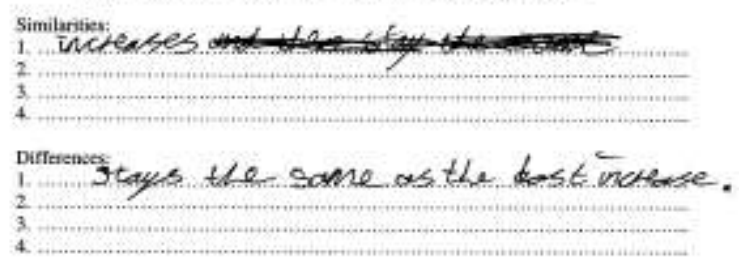

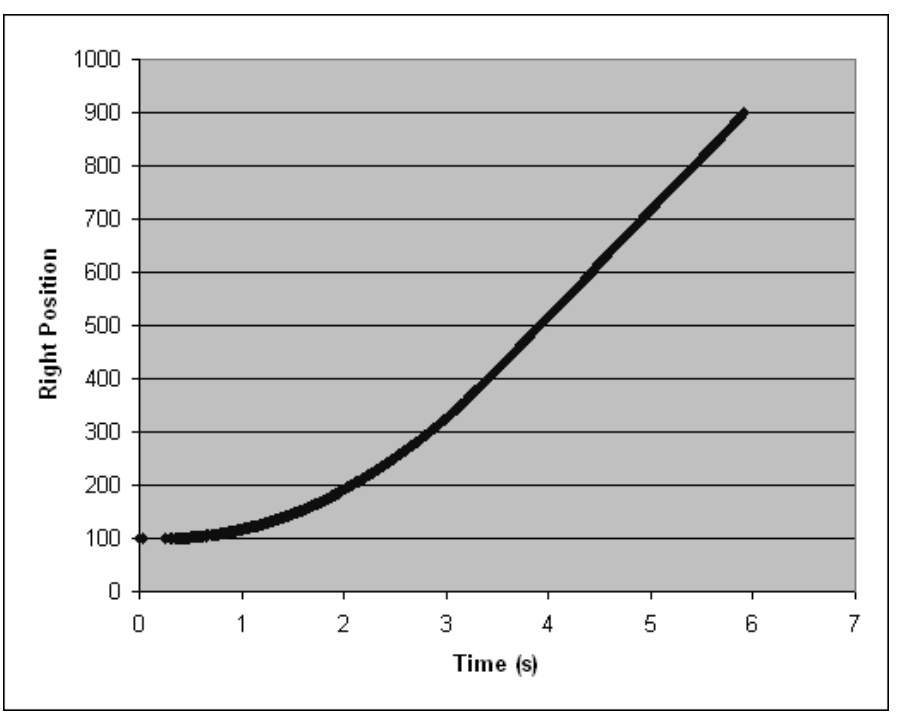


Exploring the mathematics of motion through construction and collaboration (2006) Journal of Computer Assisted Learning, 22, pp114-136

Figure 8.

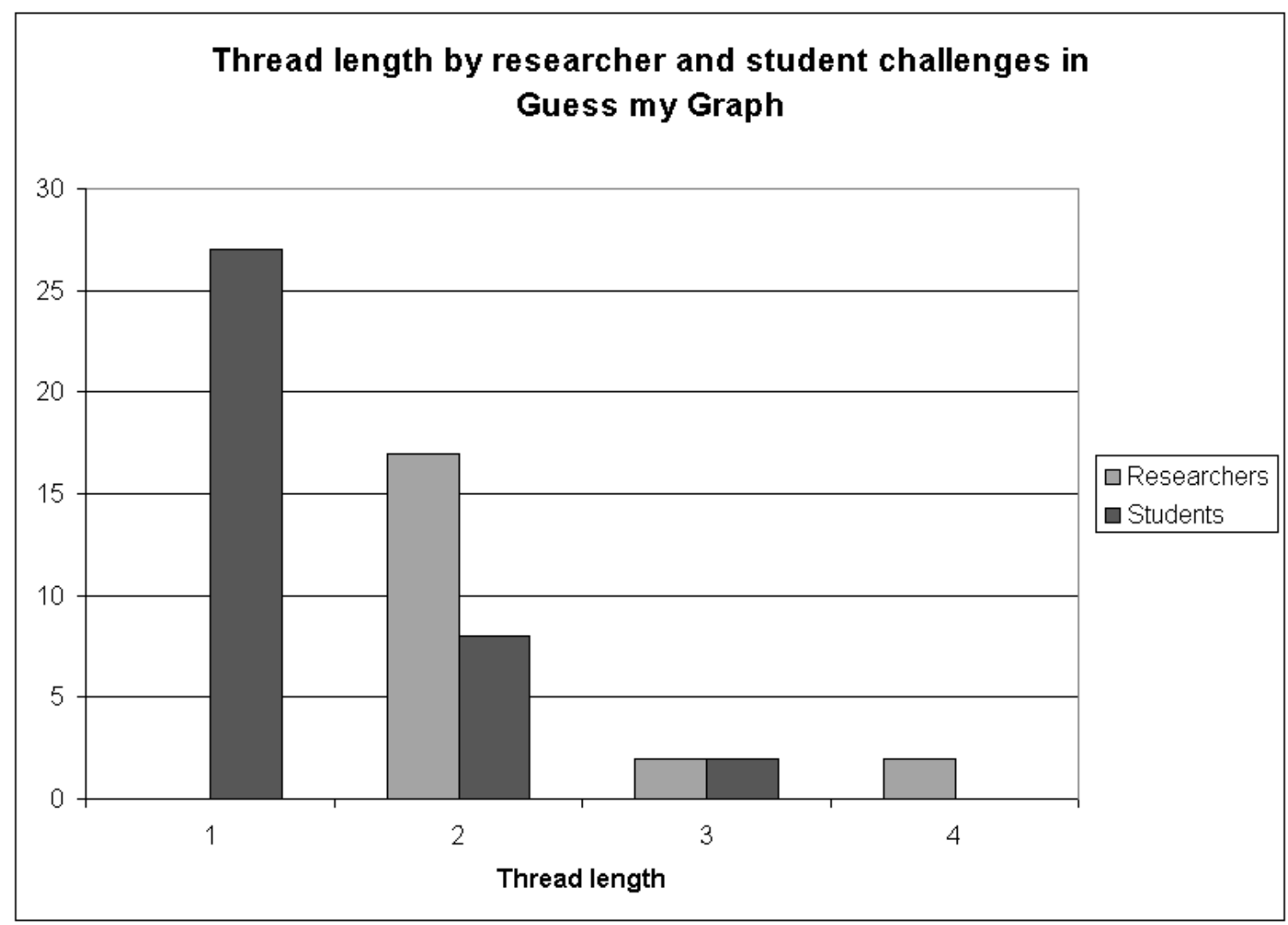

Figure 9. 
Exploring the mathematics of motion through construction and collaboration (2006) Journal of Computer Assisted Learning, 22, pp114-136

\section{WebLabs}

Welcome

Sites

Tools

Teacher guide

Help

make my graph chal.

Created by michael - Topic Group: Lunar Lander - Created: 28-02-05 - Modified: 28-02-05

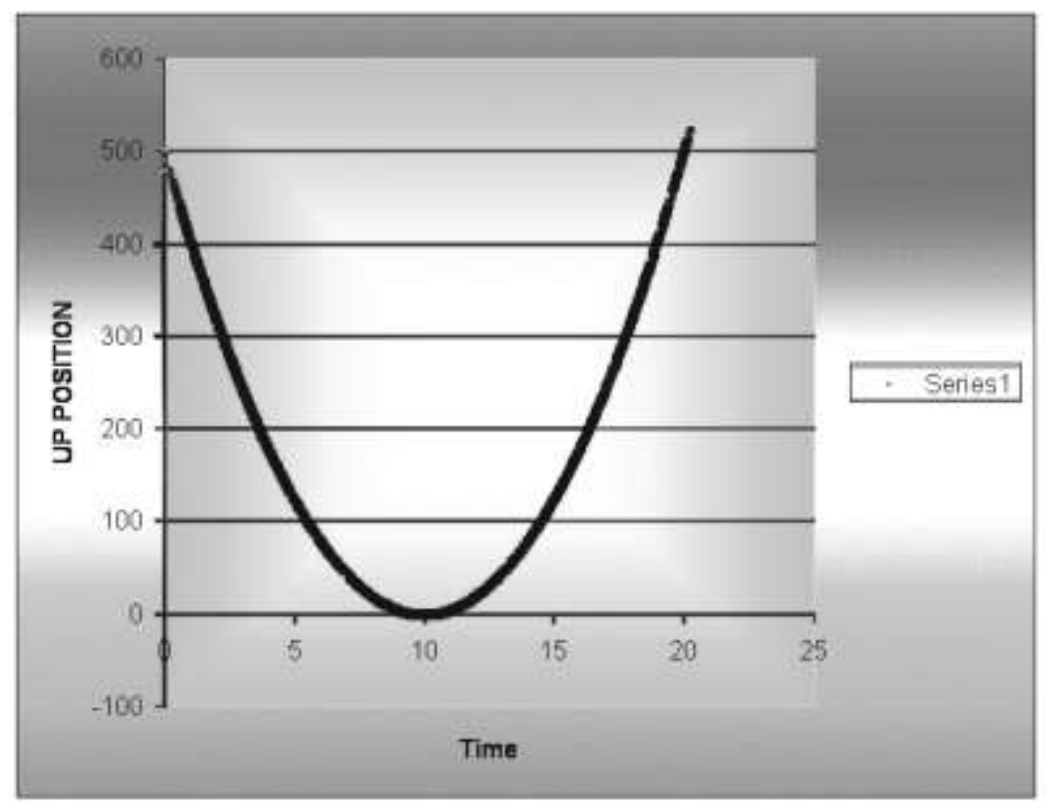

Figure 10. 
Exploring the mathematics of motion through construction and collaboration (2006) Journal of Computer Assisted Learning, 22, pp114-136

Comment

\section{I have a conjecture...}

Posted by: sodapop at: 08-03-05

First of all we began by seeing how much the speed affects the up position every second. We came to the conclusion that a speed value of 1 would add 1 Adward to the up postion (The same effect could happen. with right speed and right position). The the was so for minus numbers which we used. From this we found out that to reach postion 0 from 500 in 10 seconds, you had to have an up speed of -50 . But for it: to come back up to its starting position, you had to have a positive acceleration. For it to happen in the time that you did it, you're acceleration would have to be 10 .

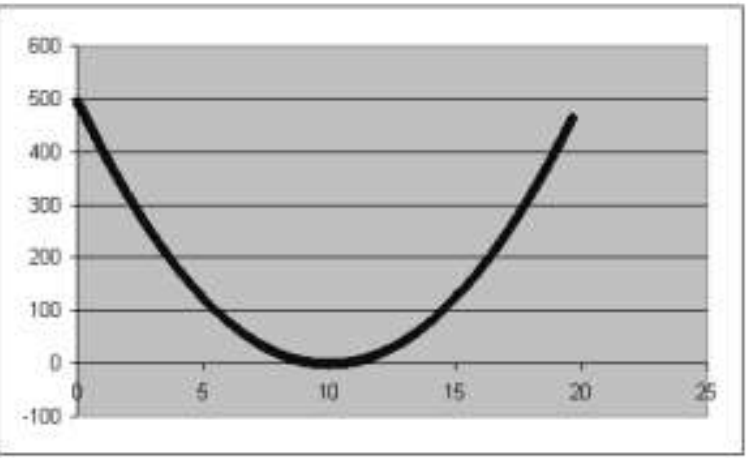

Figure 11.

Inital Up Position set as 500, Up Speed set as -200, and Acceleration set as 20.

The lander starts on a negative decent, and after a while the acceleration counter-acts the up speed, and this then becomes a positive number, constantly rising.

We set our up position as 1000 , as opposed to 500 .

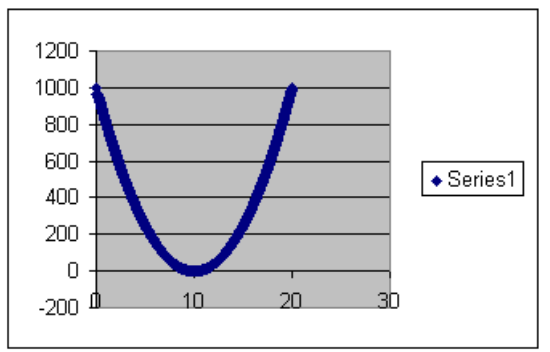

Figure 12. 
Exploring the mathematics of motion through construction and collaboration (2006) Journal of Computer Assisted Learning, 22, pp114-136

fuel : 4710

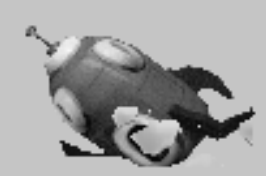

$$
\begin{aligned}
& \text { 'Shift' = boost } \\
& { }^{\prime\langle-'}=\text { left } \\
& \left.\left.{ }^{\prime}\right\rangle\right\rangle^{\prime}=\text { right }
\end{aligned}
$$

Figure 13. 
Exploring the mathematics of motion through construction and collaboration (2006) Journal of Computer Assisted Learning, 22, pp114-136

\section{Figure Legends}

Figure 1. Outline of the seven lunar lander activities. The majority of the activities (first five of seven) are based around constructing and interpreting kinematics graphs, whereas the sixth activity introduces force and mass into the modelling equation (i.e. consideration of the causes of motion), concepts that are then used in the final gamebuilding activity.

Figure 2. A typical setup of the student's ToonTalk environment when working on the first two activities. The lunar lander is shown at top left, with its Up (position) and Up Speed sensors at top right. Below these built-in ToonTalk sensors is the acceleration tool. Shown at bottom is the Export to Excel tool, to use this students simply take a copy of one of the sensors and give it to the 'bird' which will then record the data to the windows clipboard, ready to be pasted into Excel. The programmer's hand is at bottom right.

Figure 3. Example screenshot from the predicting graphs after observing motion activity. Car 1 has been taken out of the box and placed on the ground, along with its Right (position) and Right Speed sensors. Students were instructed to set certain position and speed values and observe the resulting motion. The four cars had been given simple behaviours of constant or accelerated motion. 
Exploring the mathematics of motion through construction and collaboration (2006) Journal of Computer Assisted Learning, 22, pp114-136

Figure 4. An example set of matching different descriptions cards showing the corresponding narrative, position-time graph, velocity-time graph and ToonTalk sensor representations of the same motion event.

Figure 5. The booster tool provided to students. The lunar lander is taken out of the box and placed on the floor. 'Gravity' and the 'Force' can be set simply by typing numbers on the controls. When the 'shift' key is pressed, the 'Boost acceleration' is determined. The 'Gravity' setting simply accelerates the lander by that value. The mass of the lander is determined by its size, which can be directly controlled using the built-in ToonTalk bicycle pump tool.

Figure 6. Webreport published by two London students on defining a unit for ToonTalk screen relative position.

Figure 7. Lance's prediction graph for a car undergoing constant acceleration. $\mathrm{He}$ corrected his graph after seeing the actual data plotted in Excel, and noted that he confused speed with distance (position). Under differences he has written 'I forgot I was measuring speed vs time, not distance'. 
Exploring the mathematics of motion through construction and collaboration (2006) Journal of Computer Assisted Learning, 22, pp114-136

Figure 8. Mike's prediction for the car that accelerates to a constant speed, along with the actual data plotted in Excel. The initial value for the right position is arbitrary - the graph shows that Mike chose to start it 100 units from the left of the screen.

Figure 9. The number of comments per thread for the challenges set by researchers and students in the Guess my graph challenge.

Figure 10. Guess my graph challenge posted by a Cypriot student.

Figure 11. A response to the Cypriot challenge. Note how this group has continued to use the term 'Adwards' that was invented by two students some weeks previously.

Figure 12. Third response, note how the start and end points are different to the challenge (Figure 10).

Figure 13. A student modification of the ToonTalk lunar lander game. The game features clockwise from top left: fuel readout (added by the students), lunar lander, score readout, landing pad, and instructions for play at bottom left. 
Exploring the mathematics of motion through construction and collaboration (2006) Journal of Computer Assisted Learning, 22, pp114-136

\section{Appendix A: Pre and post-activity individual assessment}

\section{Question 1:}

To the right is a graph of an object's motion. Which sentence is the best interpretation?
(A) The object is moving with a constant, non-zero acceleration.
(B) The object does not move.
(C) The object is moving with a uniformly increasing velocity.
(D) The object is moving with a constant velocity.
(E) The object is moving with a uniformly increasing acceleration.

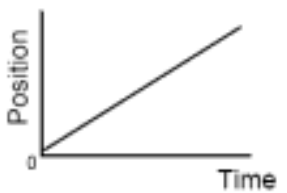

Question 2:

Here is a graph of an object's motion. Which sentence is a correct interpretation?

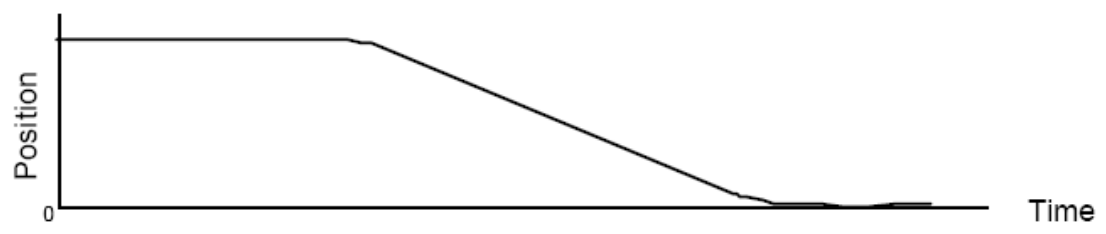

(A) The object rolls along a flat surface. Then it rolls forward down a hill, and then finally stops.

(B) The object doesn't move at first. Then it rolls forward down a hill and finally stops.

(C) The object is moving at constant velocity. Then it slows down and stops.

(D) The object doesn't move at first. Then it moves backwards and then finally stops

(E) The object moves along a flat area, moves backwards down a hill, and then it keeps moving.

Question 3:

21. To the right is a graph of an object's motion. Which sentence is the best interpretation?

(A) The object is moving with a constant acceleration

(B) The object is moving with a uniformly decreasing acceleration.

(C) The object is moving with a uniformly increasing velocity.

(D) The object is moving at a constant velocity.

(E) The object does not move.

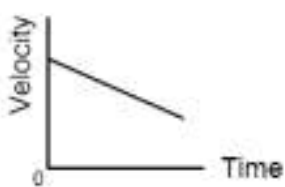

Question 4:

An object starts from rest and undergoes a positive, constant acceleration for ten seconds. It then continues on with a constant velocity. Which of the following graphs correctly describes this situation?

(A)

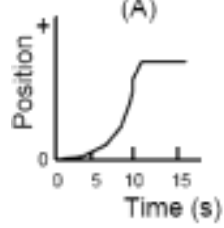

(B)

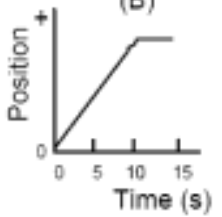

(C)

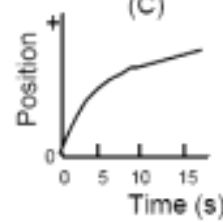

(D)

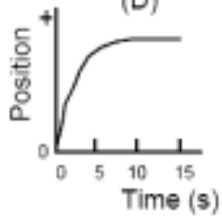

(E)

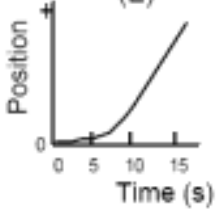


Exploring the mathematics of motion through construction and collaboration (2006) Journal of Computer Assisted Learning, 22, pp114-136

\section{Question 5:}

12. Consider the following graphs, noting the different axes:

(1)

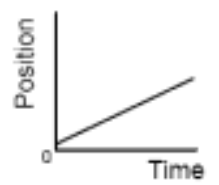

(II)

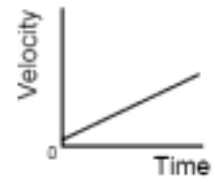

(III)

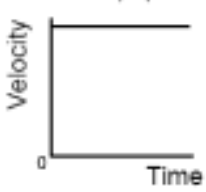

(IV)

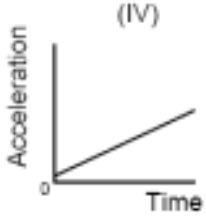

(V)

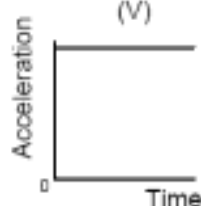

Which of these represent(s) motion at constant velocity?
(A) I, II, and IV
(B) I and III
(C) II and V
(D) IV only
(E) $V$ only

\section{Question 6:}

19. Consider the following graphs, noting the different axes:

(I)

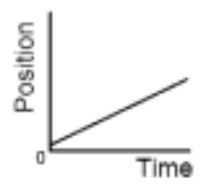

(II)

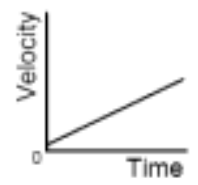

(III)

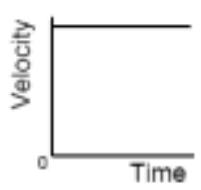

(IV)

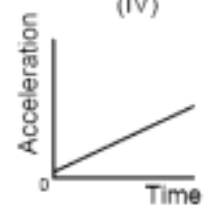

(v)

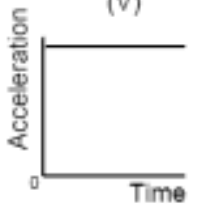

Which of these represent(s) motion at constant, non-zero acceleration?
(A) I, II, and IV
(B) I and III
(C) II and V
(D) IV only
(E) $\quad \mathrm{only}$

\section{Question 7:}

When is the acceleration most negative?
(A) $\mathrm{R}$ to $\mathrm{T}$
(B) $\mathrm{T}$ to $\mathrm{V}$
(C) $\mathrm{V}$
(D) $X$
(E) $X$ to $Z$

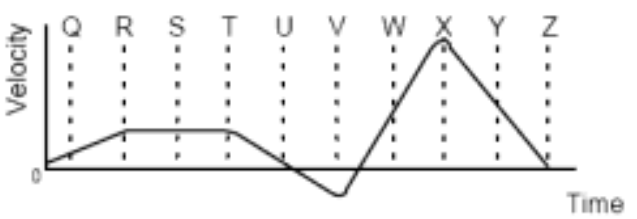


Exploring the mathematics of motion through construction and collaboration (2006) Journal of Computer Assisted Learning, 22, pp114-136 